a) Achieving pregnancy

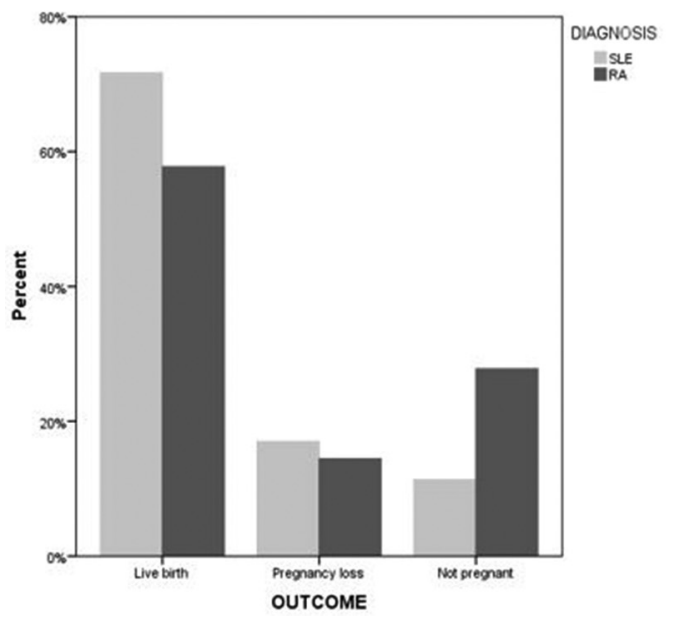

b) Kaplan-Meier plot

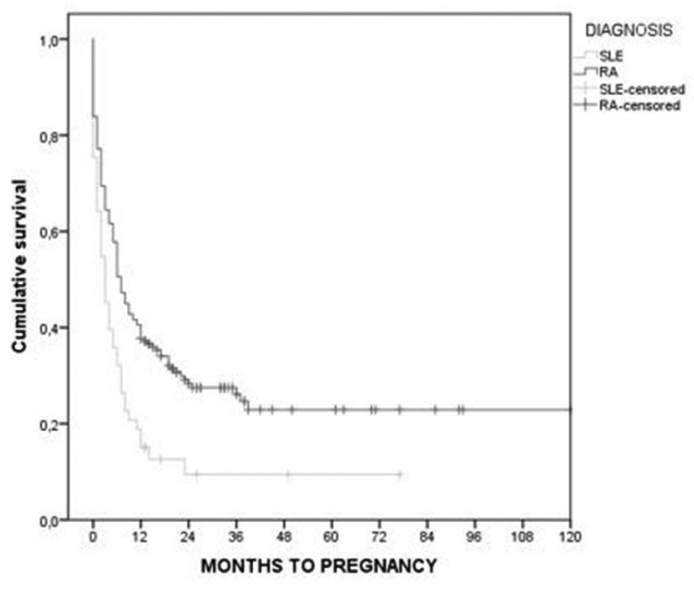

Abstract PS4:78 Figure 1 Pregnancy outcome (a) and Kaplan-Meier plot (b) with TTP as dependent variable and achieved pregnancy as event, comparing woman with SLE or RA

Objectives To examine possible differences in the ability to get pregnant and time to pregnancy (TTP) in women with systemic lupus erythematosus (SLE) and rheumatoid arthritis (RA).

Methods Data from RevNatus, a Norwegian nationwide observational register of women with rheumatic diseases planning pregnancy was used. We compared the number of women with SLE and RA achieving pregnancy, TTP and pregnancy outcome (live birth or pregnancy loss). Fifty-three women with SLE and 180 women with RA with a pregnancy wish had follow-up until pregnancy and known pregnancy outcome or at least one year if not achieving pregnancy. With cox regression we adjusted for maternal age, parity and use of disease- modifying antirheumatic drugs (DMARDs).

Results The two groups were similar concerning maternal age, parity, smoking, BMI, educational level, prior pregnancy loss and prior preeclampsia and/or preterm birth. Women with SLE had longer disease duration $(p=0.001)$, more often active disease $(p=0.002)$ and more often used a DMARD $(\mathrm{p}<0.001)$. Live birth occurred in $38(71.7 \%)$ women with SLE and $104(57.5 \%)$ women with RA, while pregnancy loss was experienced in $9(17.0 \%)$ and 26 (14.4\%), respectively. Six (11.3\%) SLE-women and 50 (27.8\%) RA-women did not achieve pregnancy during follow-up (Figure 1a). Women with SLE had almost doubled pregnancy rate compared to women with RA (pregnancy ratio 1.91 , CI 1.27 to $2.88, \mathrm{p}=0.002$ ), and when succeeding they also had a substantially shorter mean TTP (3.9 vs 6.2 months, $p=0.017$ ) (Figure 1b). Sixtyfive $(65 / 180,36.1 \%)$ RA-women and eight $(8 / 53,15.1 \%)$ SLE-women had a TTP (or censoring) exceeding one year $(\mathrm{p}=0.006)$, indicating subfertility.

Conclusions Women with SLE more often achieve pregnancy and have shorter time to pregnancy compared to women with RA.

\section{PS4:79 LONG-TERM FOLLOW-UP OF 320 CHILREN BORN TO MOTHERS WITH SYSTEMIC AUTOIMMUNE DISEASES: A MULTICENTRE SURVEY FROM 24 RHEUMATOLOGY CENTRES IN ITALY}

${ }^{1} \mathrm{MG}$ Lazzaroni, ${ }^{1} \mathrm{C}$ Nalli, ${ }^{1} \mathrm{~L}$ Andreoli, ${ }^{1} \mathrm{C}$ Carini, ${ }^{1} \mathrm{~F}$ Dall'Ara, ${ }^{2} \mathrm{M}$ Rodrigues, ${ }^{3} \mathrm{E}$ Bartoloni Bocci, ${ }^{3} \mathrm{R}$ Gerli, ${ }^{4} \mathrm{CB}$ Chighizola, ${ }^{4} \mathrm{M}$ Gerosa, ${ }^{4} \mathrm{PL}$ Meroni, ${ }^{4} \mathrm{~L}$ Sinigaglia, ${ }^{5} \mathrm{P}$ Conigliaro, ${ }^{5} \mathrm{R}$ Perricone, ${ }^{6} \mathrm{~A}$ Corrado, ${ }^{6} \mathrm{~F}$ Cantatore, ${ }^{7} \mathrm{~S}$ D'Angelo, ${ }^{8} \mathrm{M}$ Favaro, ${ }^{8} \mathrm{M}$ Larosa, ${ }^{8} \mathrm{~A}$ Doria, ${ }^{8} \mathrm{~A}$ Ruffatti, ${ }^{9} \mathrm{E}$ Generali, ${ }^{9} \mathrm{C}$ Selmi, ${ }^{10} \mathrm{M}$ Meroni, ${ }^{10} \mathrm{M}$ Cutolo, ${ }^{11} \mathrm{M}$ Padovan, ${ }^{11} \mathrm{M}$ Govoni, ${ }^{12} \mathrm{G}$ Pazzola, ${ }^{12} \mathrm{C}$ Salvarani, ${ }^{13} \mathrm{~S}$ Peccatori, ${ }^{14} \mathrm{I}$ Prevete, ${ }^{14} \mathrm{G}$ Minisola, ${ }^{14} \mathrm{GD}$ Sebastiani, ${ }^{15} \mathrm{~A}$ Brucato, ${ }^{15,16} \mathrm{~V}$ Ramoni, ${ }^{16} \mathrm{R}$ Caporali, ${ }^{16} \mathrm{C}$ Montecucco, ${ }^{17} \mathrm{C}$ Tani, ${ }^{17} \mathrm{~V}$ Signorini, ${ }^{17} \mathrm{M}$ Mosca, ${ }^{18} \mathrm{M}$ Trevisani, ${ }^{18} \mathrm{~N}$ Malavolta, ${ }^{19} \mathrm{M}$ Vadacca, ${ }^{19} \mathrm{~A}$ Afeltra, ${ }^{20} \mathrm{E}$ Vivaldelli, ${ }^{20} \mathrm{~A}$ Maier, ${ }^{21} \mathrm{E}$ Visalli, ${ }^{21} \mathrm{R}$ Foti, ${ }^{22} \mathrm{~L}$ Zuliani, ${ }^{22} \mathrm{~A}$ Gabrielli, ${ }^{23} \mathrm{C}$ Campochiaro, ${ }^{23} \mathrm{E}$ Baldissera, ${ }^{23} \mathrm{MG}$ Sabbadini, ${ }^{24} \mathrm{~N}$ Romeo, ${ }^{1} \mathrm{~A}$ Tincani. ${ }^{1}$ University and Spedali Civili of Brescia, Italy; ${ }^{2}$ Centro Hospitalar e Universitário de Coimbra, Coimbra, Portugal; ${ }^{3}$ Azienda Ospedaliera of Perugia, Italy; ${ }^{4}$ Istituto Ortopedico Gaetano Pini, Milano, Italy; ${ }^{5}$ Policlinico Tor Vergata, Roma, Italy; ${ }^{6}$ Ospedali Riuniti of Foggia, Foggia, Italy; ${ }^{7}$ Ospedale San Carlo, Potenza, Italy; ${ }^{8}$ University and Azienda Ospedaliera of Padova, Italy; ${ }^{9}$ Humanitas, Milano, Italy; ${ }^{10}$ University of Genova, IRCCS San Martino, Genova, Italy; ${ }^{11}$ University and Azienda Ospedaliera of Ferrara, Italy; ${ }^{12}$ Azienda Ospedaliera ASMN, Istituto di Ricovero e Cura a Carattere Scientifico, Reggio-Emilia, Italy; ${ }^{13}$ Azienda Provinciale Servizi Sanitari, Trento, Italy; ${ }^{14}$ A.O. San Camillo, Roma, Italy; ${ }^{15}$ Ospedale Papa Giovanni XXXIII, Bergamo, Italy; ${ }^{16}$ University and Policlinico San Matteo of Pavia, Italy; ${ }^{17}$ University of Pisa, Italy; ${ }^{18}$ Policlinico S.OrsolaMalpighi, Bologna, Italy; ${ }^{19}$ University Campus Biomedico, Roma, Italy; ${ }^{20}$ Ospedale of Bolzano, Italy; ${ }^{21}$ Policlinico Vittorio Emanuele-Ferrarotto-Bambino Gesù, Catania, Italy; ${ }^{22}$ Ospedali Riuniti of Ancona, Italy; ${ }^{23}$ Ospedale San Raffaele, Milano, Italy; ${ }^{24}$ Ospedale S. Croce e Carle, Cuneo, Italy

\subsection{6/lupus-2018-abstract.124}

Background Rheumatic Diseases (RD) frequently affect women during reproductive age, therefore counselling on family planning is crucial for their quality of life. Children's outcome is a major topic, but no large studies are available. This study aimed at assessing the long-term health conditions of children born to women with RD.

Methods 24 Italian Rheumatology Centres distributed the questionnaire (65 multiple-choice and 12 open-answer 
Abstract PS4:79 Table 1 Autoimmune/inflammatory diseases and neurophychiatric disorders in 320 children, distributed according to maternal diagnosis and timing of pregnancy. CA: chronic arthriitis; CTD: connective tissue diseases; SGA: small for Gestational Age. LD: learning disabilities (LD)

\begin{tabular}{|c|c|c|}
\hline & $\begin{array}{l}\text { Children born to women with CA } \\
\qquad(\mathrm{n}=113)\end{array}$ & $\begin{array}{l}\text { Children born to women with CTDs } \\
\qquad(n=207)\end{array}$ \\
\hline \multicolumn{3}{|c|}{ LEARNING DISABILITIES AND NEURODEVELOPMENTAL DISORDERS $n=11 / 320$ (3.4\%) } \\
\hline $\begin{array}{l}\text { Born BEFORE } \\
\text { maternal } \\
\text { diagnosis }\end{array}$ & $\begin{array}{l}1 / 84(1.2 \%) \\
1 \text { "slow learner" } \\
\text { (a SGA female) }\end{array}$ & $\begin{array}{c}5 / 144 \text { (3.5\%) } \\
3 \text { LD } \\
1 \text { Attention Deficit Hyperactivity Disorder } \\
1 \text { Autism Spectrum Disorder }\end{array}$ \\
\hline \begin{tabular}{|l|} 
Born AFTER \\
maternal \\
diagnosis
\end{tabular} & $0 / 29(0 \%)$ & $\begin{array}{c}5 / 53(7.9 \%) \\
3 \text { LD } \\
1 \text { Attention Deficit Hyperactivity Disorder } \\
1 \text { Attention Deficit Hyperactivity Disorder + LD }\end{array}$ \\
\hline \multicolumn{3}{|c|}{ AUTOIMMUNE/INFLAMMATORY DISEASES $n=12 / 320$ (3.7\%) } \\
\hline $\begin{array}{l}\text { Born BEFORE } \\
\text { maternal } \\
\text { diagnosis }\end{array}$ & $\begin{array}{l}\qquad 3 / 84(3.6 \%) \\
1 \text { Juvenile Rheumatoid Arthritis } \\
1 \text { Diabetes Mellitus type } 1 \\
\text { I Coeliac Disease }\end{array}$ & $\begin{array}{l}4 / 144(2.8 \%) \\
1 \text { Chronic Autoimmune Thyroiditis } \\
3 \text { Coeliac Disease }\end{array}$ \\
\hline \begin{tabular}{|l|} 
Born AFTER \\
maternal \\
diagnosis
\end{tabular} & $\begin{array}{l}1 / 29(3.4 \%) \\
1 \text { Coeliac Disease }\end{array}$ & $\begin{array}{l}1463(6.3 \%) \\
3 \text { Fever of Unknown Origin } \\
3 \text { Coeliac Disease }\end{array}$ \\
\hline
\end{tabular}

questions) to consecutive patients (aged 18-55) during September 2015. Data were analysed dividing children upon maternal diagnosis: Chronic Arthritides (CA) and Connective Tissue Diseases (CTD).

Results Data were collected for 320 children born to 184 mothers (63 CA and $121 \mathrm{CTD})$. At the time of interview, children had a mean age of $17.1 \pm 9.6$ years. Pre-term delivery $(<37 \mathrm{w})$ was observed in 72 cases $(22.5 \%)$, including $13(4 \%)$ cases born $<34 \mathrm{w}$.

The occurrence of an autoimmune/inflammatory disease (AIID) and/or neurodevelopmental disorders (ND)/learning disabilities (LD) is reported in table 1.

Twelve children (3.7\%) were diagnosed with an AIID, mostly coeliac disease (8/12, 67\%). Eleven children $(3.4 \%)$ were diagnosed as having a ND and/or LD by a Paediatric Neuropsychiatrist. Data of in utero exposure to maternal autoantibodies and/or anti-rheumatic drugs were retrieved for 280 children $(87.5 \%)$ and a comparison was performed between affected $(n=11)$ and not-affected children $(n=258)$. No association was found with $\mathrm{ND} / \mathrm{LD}$ and in utero exposure to autoantibodies (ANA, anti-Ro, anti-dsDNA, aPL) or drugs (HCQ, AZA or steroids), neither with sex, preterm birth, birth weight or maternal diagnosis.

Conclusions The long-term follow-up of children born to mothers with $\mathrm{RD}$ did not raise particular concerns in terms of relevant health problems. In particular, each AIID did not display a significantly increased frequency as compared to the literature. Children with $\mathrm{ND} / \mathrm{LD}$ had a tendency to cluster in the group of mothers with CTD, especially after maternal diagnosis, with a higher frequency as compared to GPP (7.9\% vs 3\%).

Our data suggest that the development of $\mathrm{ND} / \mathrm{LD}$ in children of patients with $\mathrm{RD}$ cannot be linked exclusively to maternal disease. The results of this study can be reassuring for patients with RD about problems in the offspring possibly related to their disease.

\section{PS4:80 HYDROXYCHLOROQUINE IN LUPUS PREGNANCY: A META-ANALYSIS OF INDIVIDUAL PARTICIPANT DATA}

${ }^{1} \mathrm{~A}$ Eudy, ${ }^{2} \mathrm{M}$ Petri, ${ }^{3} \mathrm{R}$ Fischer-Betz, ${ }^{4} \mathrm{~A}$ Mokbel, ${ }^{5} \mathrm{C}$ Nalli, ${ }^{5} \mathrm{~L}$ Andreoli, ${ }^{5} \mathrm{~A}$ Tincani, ${ }^{6} \mathrm{Y}$ Molad, ${ }^{7} \mathrm{D}$ Gladman, ${ }^{8} \mathrm{M}$ Urowitz. ${ }^{1}$ Duke University Medical Centre - Department of Medicine, Durham, USA; ${ }^{2}$ Johns Hopkins University School of Medicine - Department of Medicine, Baltimore, USA; ${ }^{3}$ University Hospital Düsseldorf - Department of Rheumatology, Düsseldorf, Germany; ${ }^{4}$ Cairo University Hospital - Department of Rheumatology and Rehabilitation, Cairo, Egypt; ${ }^{5}$ Ospedali Civili and University of Brescia - Rheumatology and Clinical Immunology, Brescia, Italy; ${ }^{6}$ Tel Aviv University - Rheumatology Unit, Tel Aviv, Israel; ${ }^{7}$ University of Toronto - Rheumatology, Toronto, Canada; ${ }^{8}$ University of Toronto - Centre for Prognosis Studies in the Rheumatic Diseases, Toronto, Canada

10.1136/lupus-2018-abstract.125 